\title{
A nationwide study of asthma correlates among adolescents in Saudi Arabia
}

Umayya Musharrafieh $^{1 \dagger}$, Hani Tamim $^{2 \dagger}$, Rana Houry ${ }^{1}$ and Fadia AlBuhairan ${ }^{3^{*}}$

\begin{abstract}
Background: Asthma is a chronic airway inflammation disease that is frequently found in children and adolescents with an increasing prevalence. Several studies are linking its presence to many lifestyle and health correlates. The objective of this study was to explore these correlates and find characteristics of self-reported asthmatics among adolescents in Saudi Arabia.

Methods: This is a cross-sectional, school-based study carried out in all 13 regions of Saudi Arabia. Sampling was randomly done from intermediate and secondary school students. Data in our study consisted of demographic characteristics, health conditions and lifestyle patterns and were compared between the two groups: asthmatics versus non-asthmatics. Comparison between the two groups was done by analyzing our data using Statistical Analysis Software SURVEYFREQ procedure (SAS Version 9; SAS Institute, Cary, NC).

Results: Among a sample of 11,348 participants, the prevalence of self-reported asthma was found to be $8.2 \%$. Various characteristics were found significantly different between the 2 groups including the gender, the weight, the family's education, and dietary patterns. Self -reported asthmatic were more likely to be males, overweight or obese, with a lower father's level of education and a higher consumption of milk and power drinks.

Conclusion: Asthma disease remains prevalent among adolescents in Saudi Arabia and requires higher awareness and better guidance for its prevention and treatment. Further efforts should focus on health promotion and lifestyle wellness to support preventive efforts of this chronic disease condition.
\end{abstract}

Keywords: Asthma, Comorbidities, Saudi Arabia, Lifestyle, Adolescents

\section{Background}

Asthma is a chronic inflammatory disease that affects the airways of the lungs. It is characterized by a hyperresponsiveness of the intrapulmonary airways and a variable resistance to airflow that could be reversible spontaneously or in response to treatment [1].

The World Health Organization estimates that 235 million people worldwide of all ages suffer from asthma [2]. With the modernization of the lifestyles and consequent urbanization,this prevalence remains on an

\footnotetext{
*Correspondence: Fadia.albuhairan@gmail.com; falbuhairan@aldaramed.com ${ }^{+}$Umayya Musharrafieh and Hani Tamim contributed equally to this work. ${ }^{3}$ Department of Pediatrics and Adolescent Medicine, AlDara Hospital and Medical Center; College of Medicine, Alfaisal University, Riyadh, Saudi Arabia Full list of author information is available at the end of the article
}

increase [3]. According to the National Institute of Health, the prevalence and severity of asthma is well associated with gender differences, with asthma being more common among males during childhood [4]. Besides its increasing prevalence, asthma has been linked to several health and lifestyle correlates, including the increasing technology and social media use by adolescents; asthmatic children have been found to use technology and spend more time on social media than nonasthmatics [5].

Asthma is among the top twenty chronic conditions for global ranking of disability-adjusted life years in children; in the mid-childhood ages 5-14 years it is among the top 10 causes. The burden of asthma on patients, family, and society is inexplicably high in low-income 
and middle income countries, where access to adequate treatment is not available. Although there is a worldwide downward trend of asthma mortality in adults and children over the past 25 years, a wide global disparity remains in years of life lost because of asthma [6].

In a recent meta-analysis, many higher comorbid conditions were found to be associated with asthma, such as cardiovascular disease [7, 8], hypertension [9], diabetes [10], allergies [11], obesity [12], metabolic and endocrine conditions [13], gastro-esophageal reflux disease [14], and urinary tract conditions [13]. Not sparing psychological aspects, adolescents with asthma are more likely to have depression and reduced quality of life [15], and are at increased risk of suffering from behavioral and psychological problems including school and cyber bullying [5].

Modern lifestyle factors and diet habits have also impacted asthma disease and frequency. While the wide fast food consumption, frequent soda intake, sedentary lifestyle and lack of physical activity and exercise have been associated with an increased asthma prevalence; milk, fruits and fish intake may have a protective association with asthma [16-18].

At another level, school performance is well associated and affected by asthma. Several studies have revealed presence of significant school problems in asthmatic children [19], and this has been partly attributed to interrupted sleep due to nocturnal asthma and nighttime awakening in affected children [20].

Although the prevalence of asthma in Saudi Arabian children and adolescents has been reported to range from 8 to $25 \%$ based on studies conducted over the past three decades [21], the characteristics of children and adolescents with asthma in relation to disease and lifestyle patterns have not been explored. Most surveys have addressed one aspect or characteristic in relation to asthma status at a time.

The objective of this study was to assess, among adolescents in Saudi Arabia, factors associated with selfreported asthma, including demographic characteristics, diet, lifestyle factors, psychological state and comorbid diseases.

\section{Methods}

\section{Jeeluna ${ }^{\circledR}$ study}

A school-based, cross-sectional study was conducted in all 13 regions of the Kingdom of Saudi Arabia (KSA) in 2011-2012 aiming to identify health risk behaviors and status among adolescents in KSA. The original sample size was calculated to be 12,000 students in intermediate and secondary schools. With a prevalence of $30 \%$, a $1 \%$ margin of error and a $99 \%$ confidence, a sample size to estimate proportions of population characteristics was determined to be 11,361 . It was further increased by $5 \%$ to justify contingencies such as no response or missing answers. Results and details of the original study were published elsewhere [22]. However, in brief, the original study assessed adolescents' health risk behaviors and health status, clinical anthropometric measurements, and laboratory investigations using data from selfadministrated questionnaires in addition to data collected by trained data-collecting teams. Schools were randomly selected from a Ministry of Education (MOE) list of registered schools, which included gender segregated intermediate and secondary schools. Sample was stratified by gender, level (intermediate or secondary), school district, and region. Various health risk behaviors were addressed, including dietary behaviors, tobacco use, bullying, sedentary lifestyle lack of safety measures, as well as the presence of comorbidities. The study was reviewed and approved by the ethics committees at King Abdullah International Medical Research Center and the MOE. Also permission was obtained from schools, and consents and assents from parents and students were obtained, respectively.

Study design:

The design of our project was a nested study for a secondary data analysis using data from the above mentioned cross-sectional survey.

For the current study, our inclusion criteria were: (1) participants aged between 10 and 18 years and (2) available information on whether individual participant was asthmatic or not. This gave us a sample of 11,348 participants. Presence of asthma was based on adolescents' self-report of whether or not they had a diagnosis of asthma.

\section{Data collection}

For our study, we extracted relevant data from the original database used in the original study. Our final data mainly consisted of: (1) demographic characteristics such as age, gender and family and economical status; (2) health conditions including comorbidities and BMIs, (3) dietary behaviors such as number of meals and different food intake, (4) violence and bullying, (5) sleep patterns, (6) tobacco use, (7) education and school performance, and (8) activities including physical activity and technology use. Body Mass Index (BMI) was categorized as it is in the Center for Disease Control and Prevention BMI charts [23] considering percentiles $<5$ th as underweight, 5 th to $<85$ th as healthy weight, 85 th to $<95$ th as overweight and $\geq 95$ th as obese. As for daily dietary patterns, 2-4 meals per day and 1-4 snacks per day were considered as a regular diet $[24,25]$.

\section{Statistical analysis}

Participants were divided in 2 groups based on presence or absence of asthma. Data were analyzed and adjusted 
for complex sampling design using Statistical Analysis Software SURVEYFREQ procedure (SAS Version 9; SAS Institute, Cary, NC). For categorical variables, we calculated frequencies and percentages, as for continuous variables, we considered means and standard deviations. Asthmatic and non-asthmatic patients' differences were detected using the chi-square test. Multivariate logistic regression analyses were carried out to identify predictors of asthma. Results were reported as odds ratio (OR), and $95 \%$ confidence interval (CI). A $p$-value $<0.05$ was used to indicate statistical significance.

\section{Results}

\section{Participant's characteristics and comorbidities}

Our final sample included 11,348 participants, with a prevalence of self-reported asthma reaching 8.2\% (95\% CI: 7.7-8.8\%). Fifty one percent of the participants were males, and $28.4 \%$ were aged between 10 and 14 years. Participants' demographic characteristics and their comorbidities are presented in Table 1.

Regarding gender, self -reported asthmatics were significantly more likely to be males as compared to nonasthmatics $(65.3 \%$ vs. $49.9 \%, p<0.001)$. As for nationality, $87.3 \%$ of participants were of Saudi Arabian origin and there were significantly more Saudi self-reported than non-Saudi asthmatics $(90.7 \%$ vs. $87.0 \%, p=0.001)$. Fathers of asthmatic adolescents had a lower rate of completing high school (54.6\% vs. $59.8 \%, p=0.003)$, and families of self-reported asthmatics had lower household incomes in comparison to non-asthmatics $(74.8 \%$ vs $70.7 \%, p=0.05)$. As for comorbidities, only $0.7 \%$ had diabetes, with no difference between asthmatics and nonasthmatics. Moreover, self-reported asthmatics had a higher rate of hematological disorders $(4.9 \%$ vs. $3.6 \%$, $p=0.05)$, allergies-other than asthma $(12.2 \%$ vs. $4.0 \%$, $p<0.001)$ and genitourinary diseases $(2.3 \%$ vs $1.1 \%, p=$ 0.002). Also self-reported asthmatic students had higher levels of BMI and higher rates of obesity (BMI $\geq 95$ th percentile) than non-asthmatics $(23.9 \%$ vs. $15.1 \%, p<$ $0.001)$.

\section{Participants' dietary patterns and lifestyle factors}

Participants' nutrition and dietary patterns as well as their lifestyle habits, including school behaviors, are presented in Table 2 . The majority of students consumed a regular number of main meals and snacks and ordered fast food with no difference between self-reported asthmatics and non-asthmatics. Only $11 \%$ consumed more than 5 serving of vegetables or/and fruits per day, while asthmatics intake of soft drinks $(63.0 \%$ vs $58.7 \%, p=$ $0.01)$ and power drinks $(26.4 \%$ vs $20.9 \%, p<0.001)$ was higher and more frequent than non-asthmatics. Also non-asthmatics consumed less milk as compared to selfreported asthmatics $(55.3 \%$ vs $50.6 \%$ did not consume

Table 1 Demographic characteristics and comorbidities of asthmatics and healthy controls

\begin{tabular}{|c|c|c|c|c|c|}
\hline & & $\begin{array}{l}\text { All } \\
(n=11,348) \%\end{array}$ & $\begin{array}{l}\text { Non-asthmatic } \\
(n=10,412) \%\end{array}$ & $\begin{array}{l}\text { Asthmatic } \\
(n=936) \%\end{array}$ & $p$-value \\
\hline \multicolumn{6}{|l|}{ Demographics } \\
\hline \multirow[t]{2}{*}{ Age (years) } & Between 10 and 14 & $3209(28.4)$ & $2930(28.2)$ & $279(29.9)$ & 0.28 \\
\hline & Between 15 and 18 & $8101(71.6)$ & $7447(71.8)$ & $654(70.1)$ & \\
\hline \multirow[t]{2}{*}{ Gender } & Male & $5808(51.2)$ & $5197(49.9)$ & $611(65.3)$ & $<0.001$ \\
\hline & Female & $5540(48.8)$ & $5215(50.1)$ & $325(34.7)$ & \\
\hline \multirow[t]{2}{*}{ Nationality } & Saudi & $9632(87.3)$ & $8794(87.0)$ & $838(90.7)$ & 0.001 \\
\hline & Non Saudi & $1400(12.7)$ & $1314(13.0)$ & $86(9.3)$ & \\
\hline Father's level of education: high school and above & & $5785(59.4)$ & $5343(59.8)$ & $442(54.6)$ & 0.003 \\
\hline Mother's level of education: high school and above & & $4563(45.1)$ & $4213(45.3)$ & $350(42.7)$ & 0.16 \\
\hline Monthly income for family $\leq 15,000$ SAR & & $4165(71.0)$ & $3768(70.7)$ & $397(74.8)$ & 0.05 \\
\hline \multicolumn{6}{|l|}{ Comorbidities } \\
\hline Diabetes & & $76(0.7)$ & $70(0.7)$ & $6(0.7)$ & 0.95 \\
\hline Hematological disorder & & $419(3.7)$ & $374(3.6)$ & $45(4.9)$ & 0.05 \\
\hline Allergies other than asthma & & $531(4.7)$ & $418(4.0)$ & $113(12.2)$ & $<0.001$ \\
\hline Genitourinary & & $137(1.2)$ & $116(1.1)$ & $21(2.3)$ & 0.002 \\
\hline \multirow[t]{4}{*}{ BMl } & Underweight & $1704(15.1)$ & $1559(15.1)$ & $145(15.6)$ & $<0.001$ \\
\hline & Healthy weight & $6190(54.9)$ & 5769 (55.7) & $421(45.2)$ & \\
\hline & Overweight & 1603 (14.2) & $1460(14.1)$ & $143(15.3)$ & \\
\hline & Obese & 1788 (15.8) & 1565 (15.1) & $223(23.9)$ & \\
\hline
\end{tabular}


Table 2 Difference in diet and nutrition patterns and lifestyle in asthma and healthy controls

\begin{tabular}{|c|c|c|c|c|c|}
\hline & & $\begin{array}{l}\text { All } \\
(n=11,348) \%\end{array}$ & $\begin{array}{l}\text { Non-asthmatic } \\
(n=10,412) \%\end{array}$ & $\begin{array}{l}\text { Asthmatic } \\
(n=936) \%\end{array}$ & $p$-value \\
\hline \multicolumn{2}{|l|}{ Regular number of main meals per day } & $9127(81.3)$ & $8388(81.4)$ & $739(79.9)$ & 0.25 \\
\hline \multicolumn{2}{|l|}{ Regular number of snacks per day } & $9489(84.5)$ & $8711(84.6)$ & $778(83.6)$ & 0.42 \\
\hline \multicolumn{2}{|l|}{ Fruits and vegetables intake ( $>5$ servings) } & $1241(11.0 \%)$ & $1123(10.8)$ & $118(12.7)$ & 0.08 \\
\hline \multicolumn{2}{|l|}{ Frequent ${ }^{\text {b }}$ Soft drinks intake } & $6648(59.1)$ & $6063(58.7)$ & $585(63.0)$ & 0.01 \\
\hline \multicolumn{2}{|l|}{ Frequent ${ }^{b}$ Power drinks intake } & $2400(21.3)$ & $2155(20.9)$ & $245(26.4)$ & $<0.001$ \\
\hline \multirow[t]{3}{*}{ Number of milk drinks per day } & 0 & $6136(54.9)$ & $5668(55.3)$ & $468(50.6)$ & \multirow[t]{3}{*}{0.02} \\
\hline & $1-2$ & $4379(39.2)$ & $3986(38.9)$ & $393(42.5)$ & \\
\hline & $>2$ & $662(5.9)$ & $598(5.8)$ & $64(6.9)$ & \\
\hline \multicolumn{2}{|c|}{ Fast food intake more than twice in the past 7 days } & $3490(31.3)$ & $3180(31.1)$ & $310(33.6)$ & 0.11 \\
\hline \multirow[t]{2}{*}{ Exercise for 30 minutes in the last 7 days } & $<3$ & $8021(71.8)$ & $7368(71.9)$ & $653(70.6)$ & \multirow[t]{2}{*}{0.40} \\
\hline & $\geq 3$ & $3154(28.2)$ & $2882(28.1)$ & $272(29.4)$ & \\
\hline Sleeping patterns & $\begin{array}{l}\text { Often }{ }^{a} \text { feels refreshed upon } \\
\text { awakening in the morning }\end{array}$ & $2723(24.5)$ & $2518(24.7)$ & $205(22.2)$ & 0.09 \\
\hline \multirow[t]{3}{*}{ Age of onset of cigarette smoking (years) } & Never & $9233(82.9)$ & $8512(83.4)$ & $721(77.7)$ & \multirow[t]{3}{*}{$<0.001$} \\
\hline & Less than 12 & $797(7.2)$ & $717(7.0)$ & $80(8.6)$ & \\
\hline & Between 12 and 18 & $1106(9.9)$ & $979(9.6)$ & $127(13.7)$ & \\
\hline \multicolumn{2}{|l|}{ Cigarette smoking in the last 30 days } & $711(6.4)$ & $637(6.2)$ & $74(8.0)$ & 0.04 \\
\hline \multicolumn{2}{|l|}{ Video game use $>2$ hours daily } & $1510(13.4)$ & $1341(13.0)$ & $169(18.1)$ & $<0.001$ \\
\hline \multicolumn{2}{|l|}{ Mobile phone use $>30$ minutes daily } & $2394(26.0)$ & $2180(25.9)$ & $214(27.8)$ & 0.24 \\
\hline \multicolumn{2}{|l|}{$\begin{array}{l}\text { Academic performance during preceding } \\
\text { school semester: above average }\end{array}$} & $10,497(95.6)$ & $9647(95.8)$ & $850(93.7)$ & 0.004 \\
\hline \multicolumn{2}{|l|}{ Frequent $^{a}$ school absenteeism } & $3302(29.6)$ & $3009(29.4)$ & $293(31.7)$ & 0.14 \\
\hline \multirow[t]{3}{*}{ Reason for school absenteeism } & Was never absent & $2292(20.4)$ & $2156(20.9)$ & $136(14.6)$ & \multirow[t]{3}{*}{$<0.001$} \\
\hline & Sickness or doctor's appointment & $5442(48.4)$ & $4885(47.4)$ & $557(59.7)$ & \\
\hline & Didn't want to come & $3510(31.2)$ & $3270(31.7)$ & $240(25.7)$ & \\
\hline
\end{tabular}

a: most of the times or always

b: daily and more than once

any milk, respectively, $p=0.02$ ). As for exercising, no significant difference was found between the two groups, as the majority of the students participated in physical activity less than 3 times a week (71.8\%). As for sleeping patterns, self-reported asthmatics more often reported feeling unrefreshed upon awakening in the morning ( $22.2 \%$ vs $24.7 \%, p=0.09)$. On the other hand, significant differences in other behaviors were found. Self-reported asthmatics reported smoking more than non-asthmatics (8.0\% vs. $6.2 \%, p=0.04)$ and were also found to start smoking at an earlier age (for less than 12 years old $8.6 \%$ vs. $7.0 \%$ and for age between 12 and 18 years $13.7 \%$ vs. 9.6\%, $p<0.001)$. Also, self-reported asthmatics spent more time on video games $(18.1 \%$ vs $13.0 \%, p<0.001)$ but with no significant differences found in the use of mobile phones. When looking at academic performance, self-reported asthmatics less frequently reported above average academic performance in comparison to nonasthmatics (93.7\% vs. 95.8\%, $p=0.004)$. Although both groups had similar frequency of school absenteeism
(29.6\%), there was a significant difference in the reasons for being absent, where asthmatics reported more absenteeism due to sickness or a doctor's appointment $(59.7 \%$ vs. $47.4 \%, p<0.001)$.

\section{Relationships with parents and peers and adolescents' mental health}

Participants' parents and peer relations and mental health are shown in Table 3. The majority perceived their relationship with both parents as being good. On the other hand, students with asthma were more likely to be frequently feeling sad or down for more than 2 weeks in the past 12 months $(17.2 \%$ vs. $14.1 \%, p=0.01)$ and to seek help $(12.1 \%$ vs. $7.9 \%, p<0.001)$. They also tended to be bullied (37.5\% vs $30.9 \%, p<0.001)$ and to bully $(44.5 \%$ vs $36.0 \%, p<0.001)$ in and outside of the school.

Multivariate analysis showing risk factors for asthma are shown in Table 4. Only variables with significant differences between asthmatics and non-asthmatics were 
Table 3 Psychological State and Parents and Peer Relations in asthma and healthy controls

\begin{tabular}{|c|c|c|c|c|}
\hline & $\begin{array}{l}\text { All } \\
(n=11,348) \%\end{array}$ & $\begin{array}{l}\text { Non-Asthmatic } \\
(n=10,412) \%\end{array}$ & $\begin{array}{l}\text { Asthmatic } \\
(n=936) \%\end{array}$ & $p$-value \\
\hline Frequently ${ }^{a}$ felt sad or down for more than 2 weeks ( 12 months) & $1601(14.4)$ & $1443(14.1)$ & $158(17.2)$ & 0.01 \\
\hline Ever sought help for feeling down (12 months) & $920(8.3)$ & $809(7.9)$ & $111(12.1)$ & $<0.001$ \\
\hline Having $>1$ sibling & $1103(11.8)$ & $997(11.6)$ & $106(14.1)$ & 0.04 \\
\hline Perception of relation with father as average & $9334(84.7)$ & $8562(84.7)$ & $772(85.2)$ & 0.66 \\
\hline Perception of relation with mother as average & $10,329(93.1)$ & $9487(93.2)$ & $842(91.9)$ & 0.15 \\
\hline Frequently feels worried & $743(6.7)$ & $677(6.6)$ & $66(7.2)$ & 0.52 \\
\hline Been bullied at least once & $3499(31.5)$ & $3152(30.9)$ & $347(37.5)$ & $<0.001$ \\
\hline Was a bully at least once & 4081 (36.7) & $3671(36.0)$ & $410(44.5)$ & $<0.001$ \\
\hline
\end{tabular}

a: most of the times or always

included in the multivariate analysis. It showed that asthmatics compared to non-asthmatics were less likely to be females (OR 0.62; 95\% CI, 0.54 to $0.73, p<0.0001$ ). Also father's level of education was significantly associated with asthma, where those who did not finish high school were more likely to be asthmatics (OR 1.24; 95\% CI, 1.08 to $1.42, p=0.002$ ). Asthmatics were more likely to consume power drinks than non-asthmatics (OR 1.18; 95\% CI, 1.01 to $1.38, p=0.04)$. Asthmatics were also found to spend $\geq 2 \mathrm{~h}$ daily on video games more often than non-asthmatics (OR 1.21; 95\% CI, 1.01 to 1.46, $p=$ 0.04). As for BMI, asthmatics tended to be more overweight or obese (OR 1.33; 95\% CI, 1.09 to $1.63, p=0.005$ and OR $1.78 ; 95 \% \mathrm{CI}, 1.50$ to $2.13, p<0.0001$, respectively). Finally, asthmatics were more likely to be engaged in bullying in the past 12 months, as compared to nonasthmatics (OR 1.20; 95\% CI, 1.04 to $1.38, p=0.01$ ).

Variables entered into the model (reference categories are underlined): gender (Male, Female), father's level of education (Did not finish high school, finished high school), BMI $(<5$ th percentile, 5th $-<85$ th percentile, 85 th - $<95$ th percentile, $\geq 95$ th percentile), smoking during last 30 days (No, Yes), milk intake (cups per day) (0, $1-2, \geq 2$ ), daily soft drink intake (No, Yes), daily powder drink intake (No, Yes), fruit and vegetables intake $(<5$ times per day, $\geq 5$ times per day), feel fresh when wake up in the morning (No, Yes), video games use per day $(<2 \mathrm{~h}, \geq 2 \mathrm{~h}$ ), previous school performance (GPA) (Less than good, Good and above), ever bullied in or out of school in the past 12 months (No, Yes), ever been bullied in or out of school in the past 12 months (No, Yes).

\section{Discussion}

Our study described self -reported asthmatic adolescents in KSA and it shed the light on their characteristics, their associated comorbidities, and their health risks. This work is among the largest studies conducted in KSA, and possibly in the region, to characterize adolescent asthmatics with respect to their co-morbidities and lifestyle habits.

Our study revealed that $8.2 \%$ of adolescents in KSA are self-reported asthmatics. This is within the range reported in previous studies (8-25\%) [21]. Our prevalence showed an increase from the previous nationwide study in 2013 conducted by Moradi-Lakeh et al. who reported the prevalence to be $4.02 \%$ [26]. Although there were no comprehensive programs for early diagnosis and appropriate management of asthma for children and adults,

Table 4 Multivariate stepwise logistic regression for factors associated with asthma

\begin{tabular}{lll}
\hline & OR (95\% Cl) & $p$-value \\
\hline Gender, female & $0.62(0.54-0.73)$ & $<0.0001$ \\
Father's level of education, did not complete high school & $1.24(1.08-1.42)$ & 0.002 \\
Daily power drink intake, yes & $1.18(1.01-1.38)$ & 0.04 \\
Academic performance during previous school semester, below average & $1.24(0.93-1.67)$ & 0.15 \\
Video games use per day, $\geq 2 \mathrm{~h}$ & $1.21(1.01-1.46)$ & 0.04 \\
Ever bullied (past 12 months), yes & $1.20(1.04-1.38)$ & 0.01 \\
BMl & & 0.12 \\
$\quad<5$ th percentile & $1.17(0.96-1.43)$ & 0.005 \\
$\quad$ 85th - <95th percentile & $1.33(1.09-1.63)$ & $<0.0001$ \\
$\quad \geq 95$ th percentile & $1.78(1.50-2.13)$ & \\
\hline
\end{tabular}


the impact of several programs such as the Asthma Insights and Reality in the Kingdom of Saudi Arabia (AIRKSA) launched in 2008 by the Ministry of Health may have had a role in increasing asthma awareness and contributing to the current increase in diagnosis [27]. Other possible explanations could be related to smoking. Asthma has been linked to smoking, and the prevalence of smoking among Saudi citizens is on the rise $[28,29]$. Recent epidemiological studies in Saudi Arabia revealed an increasing prevalence of asthma the past three decades that may be attributed to rapid lifestyle changes related to the modernization of Saudi society, changes in dietary habits, and exposure to environmental factors, such as indoor allergens, dust, sand storms and tobacco. Additionally, awareness of the disease can affect its prevalence and severity in a population [30].

Similar to other studies $[4,31,32]$, our study revealed gender differences, with male adolescents being more likely to be self-reported asthmatics than females. This male preponderance to asthma has been explained by differential growth of lung/airway size, and immunological differences [33].

Similar to others' reports $[15,34,35]$, we found that self -reported asthma was associated with lower socioeconomic backgrounds. This is very important to consider as higher-educated parents may have more asthma knowledge that enables them to provide better care for their asthmatic children and be better equipped to provide the appropriate care [36].

The co-morbidities and various health conditions associated with asthma can significantly affect asthma and be affected by asthma [13, 37]. Our results revealed that self -reported asthma is more likely to be found in children and adolescents who are overweight or obese. The prevalence of asthma has increased worldwide among obese children, adolescents and adults regardless of ethnic origins [38-40]. In a study conducted in KSA in 2014, there was an association between asthma and obesity in Saudi children [41]. This relationship between obesity and asthma has been discussed in several studies, and is currently considered to be a risk factor for asthma [42]. Overweight and obese subjects tend to develop asthma symptoms more due to their shallower breathing patterns as compared to healthy weight subjects. This could be due to more than one aspect; overweight subjects have more fat tissue keeping less space for their lungs to inflate, and they have more leptin and other hormones released from fat tissue resulting in higher inflammation in the airways [43]. Similarly obese subjects were found to have the asthma-like phenotype [42].

Other risk factors instituted for having asthma and allergic disorders was diet [44]. As the environmental changes, eating pattern changes, and lifestyles alterations have sewed up, asthma prevalence was concomitantly on increase [45]. Notably, the traditional diet constituting of high fiber diet and high milk intake have been transformed to a modern diet rich in preserved refined sugar and containing less dietary fiber [44].

Self-reported asthmatics' intake of power drinks is significantly higher than their healthy counterparts. There is scarcity of information in the literature to address this habit, and the relationship between asthmatics and consumption of power drinks remains vague. Nevertheless, many studies suggest that asthmatic children and adolescents are more likely to fall asleep during the day and to feel tired and powerless due to the wheezing that occurs at night and their inability to sleep well [46, 47]. We speculate whether this tiredness and sleepiness and lack of power felt by asthmatic patients are the driving factors for the consumption of more power drinks and the need for increased caffeine intake. Interestingly, energy drinks are known to be high in caffeine and sugar, in addition to other pharmaceutical and herbal stimulants [48], and this may raise dramatically blood glucose leading to unhealthy food craving, fatigue and irritation [49]. Thus asthmatics may enter an unhealthy vicious cycle of consuming more sugar that will increase their BMI leading to more power drinks consumption to recover their energy. The consequent result of increase in body weight will exacerbate their asthma symptoms and disturb further their sleep. In addition, power drinks are known to be rich in caffeine, a central nervous system stimulant from the xanthine class known to improve airway function and relieve asthma symptoms and exacerbation [50]. We wonder if this physiologic effect has in any way played an indirect role in the high consumption of power drinks among our asthmatics.

As for consumption of milk, the relation between asthma and drinking milk did not show on the multivariate analysis. This is not in agreement with the report of Hijazi et al. in 2000 [51], which showed an inverse linear relationship between asthma and the intake of milk in Saudi children. While studies have shown a protective effect of farm milk consumption on asthma [52, 53], based on which clinicians may be advising their asthmatic patients to drink more milk, our study failed to show any effect or correlation between drinking milk and asthma disease.

The literature shows strong links between asthma and lifestyle factors, school behaviours, children's' psychological state and violence. Poongadan et al. showed an increasing association between sedentary lifestyle and asthma, and reported that asthmatics watch more TV and have increasing mental stress [54]. This was not the case in our study and this association was not significant.

Although self -reported asthma has been found to be more significantly associated with depressive disorders, 
anxiety and being bullied [55, 56], our self-reported asthmatics were not found to be more psychologically affected nor were they more violent or bullied in the multivariate analysis. We speculate whether this could be due to a peer effect that is more supportive than bullying. This is supported by the development of prevention programs in SA that focused on education and increasing the awareness of bullying and its negative impacts $[57,58]$.

This study is an eye opener to physicians who care for and provide management to adolescents with asthma and is a reminder of the importance of viewing a health condition and an individual holistically. It is prudent to bear in mind the individual's health correlates and lifestyle as this can impact the disease and affect the quality of life. Assessment and management of asthma calls for a comprehensive care that conveys both medical treatment and healthy habits and lifestyle.

\section{Limitations}

Our study had some limitations that ought to be addressed; asthma was identified by adolescents' selfreport. Some adolescents, especially the younger ones, may not have necessarily been familiar with having a diagnosis of asthma. Therefore, an element of underreporting may exist. Furthermore, due to the nature of this study, we have been able to identify correlates; causality may not be inferred.

\section{Conclusion}

Asthma is an increasingly prevalent disease in Saudi Arabia, affecting males more than females and adolescents of lower socioeconomic backgrounds. Being a chronic disease, there is a need to address asthma awareness specifically in relation to adolescents' eating and drinking habits. More education to asthmatics and their families is needed to address the risks or protective effects of some dietary items such as power drinks and milk.

\section{Abbreviations \\ KSA: Kingdom of Saudi Arabia; MOE: Ministry of Education; BMI: Body Mass Index; OR: Odds Ratio; Cl: Confidence Interval; AIRKSA: Asthma Insights and Reality in the Kingdom of Saudi Arabia}

\section{Acknowledgments}

Not applicable.

\section{Authors' contributions}

FA conceived the presented idea and led the data collection. UM participated in writing the discussion part and helped shape the manuscript. HT conducted the statistical analyses. RH participated in writing the manuscript. All authors have contributed, read, discussed the results and contributed to the final manuscript.

\section{Funding}

The JEELUNA study was supported and funded by the King Abdullah International Medical Research Center (RC08-092).

\section{Availability of data and materials}

Original database used in the original study (Jeeluna Study).

\section{Ethics approval and consent to participate}

The study was reviewed and approved by the ethics committees at King Abdullah International Medical Research Center and the MOE. Permission was obtained from schools, and consents and assents from parents and students were obtained, respectively.

\section{Consent for publication}

Not applicable.

\section{Competing interests}

The authors declare that they have no competing interests.

\section{Author details}

'Department of Family Medicine, American University of Beirut Medical Center, Beirut, Lebanon. ${ }^{2}$ Department of Internal Medicine, American University of Beirut Medical Center, Beirut, Lebanon. ${ }^{3}$ Department of Pediatrics and Adolescent Medicine, AIDara Hospital and Medical Center; College of Medicine, Alfaisal University, Riyadh, Saudi Arabia.

Received: 18 June 2019 Accepted: 27 April 2020

Published online: 01 June 2020

\section{References}

1. Gina Executive Committee. Global Strategy for Asthma Management and Prevention 2006. 2006 [cited 2017 February]; Available from: http://www. seicap.es/documentos/archivos/GINA2006general.pdf.

2. WHO. Asthma, fact sheet. 2013 [cited 2017 February]; Available from: http:// www.who.int/mediacentre/factsheets/fs307/en/.

3. Odhiambo JA, et al. Urban-rural differences in questionnaire-derived markers of asthma in Kenyan school children. Eur Respir J. 1998;12(5):1 105-12.

4. National Institute of Health. Who is at Risk for Asthma? 2014 [cited 2017 February]; Available from: https://www.nhlbi.nih.gov/health/health-topics/ topics/asthma/atrisk\#.

5. Gibson-Young $L$, et al. Are students with asthma at increased risk for being a victim of bullying in school or cyberspace? Findings from the 2011 Florida youth risk behavior survey. J Sch Health. 2014;84(7):429-34.

6. Anderson HR, et al. International correlations between indicators of prevalence, hospital admissions and mortality for asthma in children. Int J Epidemiol. 2008;37(3):573-82.

7. Iribarren C, Tolstykh IV, Eisner MD. Are patients with asthma at increased risk of coronary heart disease? Int J Epidemiol. 2004;33(4):743-8.

8. Iribarren C, et al. Adult asthma and risk of coronary heart disease, cerebrovascular disease, and heart failure: a prospective study of 2 matched cohorts. Am J Epidemiol. 2012;176(11):1014-24.

9. Ben-Noun L. Characteristics of comorbidity in adult asthma. Public Health Rev. 2001;29(1):49-61.

10. Mueller NT, et al. Asthma and the risk of type 2 diabetes in the Singapore Chinese health study. Diabetes Res Clin Pract. 2013:99(2):192-9.

11. Cazzola M, et al. Asthma and comorbid medical illness. Eur Respir J. 2011; 38(1):42-9.

12. Castro-Rodriguez JA, et al. Increased incidence of asthmalike symptoms in girls who become overweight or obese during the school years. Am J Respir Crit Care Med. 2001;163(6):1344-9.

13. Su X, et al. Prevalence of comorbidities in asthma and nonasthma patients: a meta-analysis. Medicine. 2016;95(22):e3459.

14. Havemann BD, Henderson CA, El-Serag HB. The association between gastrooesophageal reflux disease and asthma: a systematic review. Gut. 2007; 56(12):1654-64.

15. Pinto Pereira LM. And T.a. Seemungal, Comorbid disease in asthma: the importance of diagnosis. Expert Review Respiratory Medicine. 2010;4(3):271-4.

16. Poongadan MN, Gupta N, Kumar R. Dietary pattern and asthma in India. Pneumonol Alergol Pol. 2016;84(3):160-7.

17. Dogra S, Baker J. Physical activity and health in Canadian asthmatics. J Asthma. 2006:43(10):795-9.

18. Park $S$, et al. Regular-soda intake independent of weight status is associated with asthma among US high school students. J Acad Nutr Diet. 2013;113(1): 106-11. 
19. Freudenberg $\mathrm{N}$, et al. The impact of bronchial asthma on school attendance and performance. J Sch Health. 1980;50(9):522-6.

20. Diette GB, et al. Nocturnal asthma in children affects school attendance, school performance, and parents\&\#39; work attendance. Arch Pediatr Adolesc Med. 2000;154(9):923-8.

21. Al-Moamary MS, et al. The Saudi initiative for asthma - 2016 update: guidelines for the diagnosis and management of asthma in adults and children. Ann Thoracic Med. 2016;11(1):3-42.

22. AlBuhairan FS, et al. Time for an adolescent health surveillance system in Saudi Arabia: findings from "Jeeluna". J Adolesc Health. 2015;57(3):263-9.

23. Center for Chronic Disease Prevention. Growth chart. 2010 [cited 201722 February]; Available from: https://www.cdc.gov/growthcharts/.

24. Dr Mercola. Two Meals a Day Is Ideal, But Which Two Is Up to You 2015 [cited 2017 January 15]; Available from: http://articles.mercola.com/sites/ articles/archive/2015/09/21/intermittent-fasting-calorie-restriction.aspx.

25. Wendy Schmid. Why You Should Eat 4 Times A Day. 2015 [cited 2017 January 15]; Available from: http://furthermore.equinox.com/articles/2 015/12/4-meals-per-day.

26. Moradi-Lakeh $M$, et al. Prevalence of asthma in Saudi adults: findings from a national household survey, 2013. BMC Pulmonary Med. 2015;15:77.

27. Arabia, M.o.H.o.t.K.o.S., The Asthma Insight and Reality in the Kingdom of Saudi Arabia (AIRKSA) study. 2007.

28. JEDDAH: Arab News. 10 million Saudi smoker by 2020. 2013 [cited 201728 February]; Available from: http://www.arabnews.com/news/453724.

29. Fida HR, Abdelmoneim I. Prevalence of smoking among secondary school male students in Jeddah, Saudi Arabia: a survey study. BMC Public Health. 2013;13(1):1010.

30. Asher Ml, et al. Worldwide time trends in the prevalence of symptoms of asthma, allergic rhinoconjunctivitis, and eczema in childhood: ISAAC phases one and three repeat multicountry cross-sectional surveys. Lancet. 2006; 368(9537):733-43.

31. Shaw $R$, et al. Risk factors for asthma symptoms in Kawerau children. New Zealand Med J. 1994;107(987):387-91.

32. Almqvist $C$, et al. Impact of gender on asthma in childhood and adolescence: a GA2LEN review. Allergy. 2008;63(1):47-57.

33. von Mutius E. Progression of allergy and asthma through childhood to adolescence. Thorax. 1996;51(Suppl 1):S3-6.

34. Litonjua AA, et al. Race, socioeconomic factors, and area of residence are associated with asthma prevalence. Pediatr Pulmonol. 1999;28(6): 394-401.

35. Cesaroni $\mathrm{G}$, et al. Individual and area-based indicators of socioeconomic status and childhood asthma. Eur Respir J. 2003;22(4):619-24.

36. Kuti BP, Omole KO. Factors associated with caregivers' knowledge about childhood asthma in Ilesa, Nigeria. Ann Nigerian Med. 2016;10(1):30.

37. Ledford DK, Lockey RF. Asthma and comorbidities. Curr Opin Allergy Clin Immunol. 2013;13(1):78-86.

38. Kopel SJ, et al. Asthma symptom perception and obesity in children. Biol Psychol. 2010;84(1):135-41.

39. Boulet LP. Asthma and obesity. Clin Exp Allergy. 2013;43(1):8-21.

40. Kim S, Camargo CA Jr. Sex-race differences in the relationship between obesity and asthma: the behavioral risk factor surveillance system, 2000. Ann Epidemiol. 2003;13(10):666-73.

41. Nahhas $M$, et al. Investigating the association between obesity and asthma in 6- to 8-year-old Saudi children: a matched case-control study. Npj Primary Care Respiratory Med. 2014;24:14004.

42. Shore SA. Obesity and asthma: implications for treatment. Curr Opin Pulm Med. 2007;13(1):56-62.

43. John Bottrell. Does Obesity Cause Asthma? 2011 [cited 201715 March]; Available from: http://www.healthcentral.com/asthma/c/52325/143507/ obesity-asthma/.

44. Devereux G, Seaton A. Diet as a risk factor for atopy and asthma. J Allergy Clin Immunol. 2005;115(6):1109-17 quiz 1118.

45. Gupta K, Verma M. Nutrition and asthma. Lung India. 2007;24(3):105-14

46. Desager KN, et al. Sleep disturbance and daytime symptoms in wheezing school-aged children. J Sleep Res. 2005;14(1):77-82.

47. Teodorescu M, et al. Correlates of daytime sleepiness in patients with asthma. Sleep Med. 2006;7(8):607-13.

48. Rath M. Energy drinks: what is all the hype? The dangers of energy drink consumption. J Am Acad Nurse Pract. 2012:24(2):70-6.
49. Haris, N. How Do Energy Drinks Affect The Body? . 2015 [cited 201721 March]; Available from: http://www.livestrong.com/article/350031-how-doenergy-drinks-effect-the-body/.

50. Welsh EJ, Bara A, Barley E, Cates CJ. Caffeine for asthma. Cochrane Database Syst Rev. 2010;20(1):CD001112. https://doi.org/10.1002/14651858.CD001112. pub2.

51. Hijazi N, Abalkhail B, Seaton A. Diet and childhood asthma in a society in transition: a study in urban and rural Saudi Arabia. Thorax. 2000;55(9):775-9.

52. Loss $\mathrm{G}$, et al. The protective effect of farm milk consumption on childhood asthma and atopy: The GABRIELA study. J Allergy Clin Immunol. 2011;128(4): 766-73 e4.

53. Lluis A, et al. Increased regulatory T-cell numbers are associated with farm milk exposure and lower atopic sensitization and asthma in childhood. J Allergy Clin Immunol. 2014;133(2):551-9 e10.

54. Poongadan MN, Gupta N, Kumar R. Lifestyle factors and asthma in India - a case-control study. Pneumonol Alergol Pol. 2016;84(2):104-8.

55. Goldney RD, et al. Asthma symptoms associated with depression and lower quality of life: a population survey. Med J Aust. 2003;178(9):437-41.

56. Janson C, et al. Anxiety and depression in relation to respiratory symptoms and asthma. Am J Respir Crit Care Med. 1994;149(4):930-4.

57. AlBuhairan FS, et al. Self reported awareness of child maltreatment among school professionals in Saudi Arabia: impact of CRC ratification. Child Abuse Negl. 2011;35(12):1032-6.

58. Freeman JG, et al. The relationship of schools to emotional health and bullying. Int J Public Health. 2009;54(Suppl 2):251-9.

\section{Publisher's Note}

Springer Nature remains neutral with regard to jurisdictional claims in published maps and institutional affiliations.
Ready to submit your research? Choose BMC and benefit from:

- fast, convenient online submission

- thorough peer review by experienced researchers in your field

- rapid publication on acceptance

- support for research data, including large and complex data types

- gold Open Access which fosters wider collaboration and increased citations

- maximum visibility for your research: over $100 \mathrm{M}$ website views per year

At BMC, research is always in progress.

Learn more biomedcentral.com/submissions 